NASA Technical Memorandum 82649

\title{
Stress Concentration in the Vicinity of a Hole Defect Under Conditions of Hertzian Contact
}

\section{LIBRARY COPY}

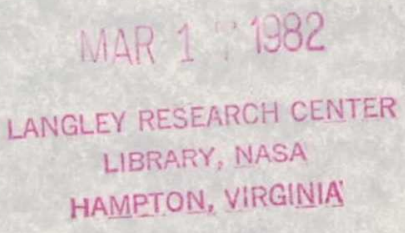

Takashi Yamamoto, Masao Eguchi, and Kosho Murayama

Lewis Research Center

Cleveland, Ohio

Prepared for the

Joint Lubrication Conference

cosponsored by the American Society of Mechanical Engineers

and the American Society of Lubrication Engineers

New Orleans, Louisiana, October 5-7, 1981 
STRESS CONCENTRATION IN THE VICINITY OF A HOLE DEFECT

UNDER CONDITIONS OF HERTZIAN CONTACT

by Takashi Yamamoto*, Masao Eguchi ${ }^{\dagger}$ and Koșho Murayama**

National Aeronautics and Space Administration

Lewis Research Center

Cleveland, Ohio

SUMMARY

Two-dimensional photoelastic stress analyses were conducted for epoxy resin models containing a hole defect under the conditions of Hertzian contact. Stress concentrations around the defect were determined as a function of several parameters. These were hole diameter, its vertical distance from the contact surface and the horizontal distance from the Hertzian contact area. Also determined was the effect of tangential traction (generated by a friction coefficient of 0.1 ) on the stress concentration.

Sharp stress concentrations ofcur in the vicinity of both the left and the right side of the hole. The stress concentration becomes more distinct the larger the hole diameter and the smaller the distance between the hole and the contact surface.

*Tokyo University of Agriculture and Technology, Tokyo, Japan and NRC-NASA Research Associate.

tAssistant, Dept. of Mech. Engineering, Tokyo University of Agriculture and Technology, Tokyo, Japan.

$\star *$ Graduate student, Dept. of Mech. Engineering, Tokyo University of Agriculture and Technology, Tokyo, Japan. 
The stress concentration is greatest when the disk imposing a normal load is located at the contact surface directly over the hole. The magnitude and the location of stress concentration varies with the distance between the Hertzian contact area and the hole. Taking into account the stress amplitude, the area which can be involved in a process of rolling contact fatigue seems to be confined to a shallow region at both sides of the hole. The effect of tangential traction is comparatively small on the stress concentration around the hole.

\section{INTRODUCTION}

Although a great deal of effort has been expended in elucidating the mechanism of failures in concentrated rolling elements, the subject is still greatly debated, particularly with respect to what stresses are the critical ones causing failure.

Most existing theories of contact fatigue damage are based on the classical Hertz theory and its subsurface related shear stresses. In the process of rolling contact fatigue, however, there are several important phenomena which cannot be explained satisfactorily by conventional considerations. Therefore, it has been pointed out for a long time that the mechanism must be understood in terms of several sources of stress concentration at or below the rolling contact surface.

The number of papers analyzing the stress field, assuming the discontinuity due to a defect such as a dent, an inclusion or a pre-existing crack in the contacting solid, is gradually increasing. There have been several studies of stress distribution analyses resulting from surface irregularities. Chiu and Liu presented a simple model for a furrow-shaped surface defect and analyzed the stress concentration around the defect (ref. 1). Leibensperger and Brittain assumed several kinds of asperity 
ridge models and analyzed the micro-Hertzian contact stress field in the vicinity of each asperity (ref. 2).

Recently, several attempts were made to deal with the problem of crack initiation or propagation based on fracture mechanics. Keer and coworkers presented numerical results for a cracked half-space, surface-loaded by Hertzian contact stresses and introduced possible mechanisms for crack propagation (ref. 3). Hills and Ashelby tried stress analysis, paying attention to the development of subsurface cracks and discussed the stress involved in the propagation of the crack (ref. 4 ).

There have been many experimental studies indicating that nonmetallic oxide inclusions or voids contained in the material act as the predominant stress raisers for fatigue crack initiation. There is, however, little data concerning the stress distribution around the defects. Generally speaking, stress analyses of a contact problem while considering a discontinuity are highly complicated and, therefore, it is difficult to determine the stress distribution from take off theory. This study examines the simplest contact problem assuming a circular hole-type defect in order to obtain the fundamental data for a quantitative discussion of fatigue crack initiation.

A conventional photoelastic technique was used, because it allows for the visualization of the stress concentration. In addition, the stress distribution can easily be determined with an adequate model. The characteristics of stress distribution around the hole were analyzed with respect to several parameters. These were hole diameter, depth of the hole subsurface, position of Hertzian contact area and loading conditions.

The results are discussed from the viewpoint of a mode of subsurface initiation of rolling contact fatigue. This is compared with the experimental results which have been reported concerning rolling contact phenomena. 


\section{STRESS ANALYSIS AND MODEL CONFIGURATION}

A conventional two-dimensional photoelastic technique was employed for stress analyses. A lens-system polariscope with polarizers and quarter wave plates $150-\mathrm{mm}$ in diameter was set up across the epoxy resin model which was externally loaded by the disk.

The size of the model was $110-\mathrm{mm}$ in height, $175-\mathrm{mm}$ in length and $6-\mathrm{mm}$ in thickness, as indicated in figure 1. The photoelastic sensitivity of the epoxy resin used in this study is $1.00-\mathrm{mm} / \mathrm{kg}$ and its Young's modulus is $280-\mathrm{kg} / \mathrm{mm}^{2}$.

Models were prepared from rectangular shaped epoxy-resin plates (160-mm $\times 220-m m \times 6-m m)$ available on the market for photoelastic stress analysis. The contact surface was finished longitudinally by emery paper about $0.5-\mu \mathrm{m}$ in peak-to-valley roughness after milling. A circular hole simulating a defect of a real material was made at a specified location in the plate. The plate was drilled after being clamped between two dummy plates of the same material in order to produce a burr and crack-free hole edge.

The hole diameter was chosen so that its ratio to the Hertzian contact width is as similar as possible to that frequently found in strength problems of materials used in engineering applications. The lower limitation of the hole size is, however, determined inevitably by several practical restrictions (i.e., tolerance in machining an exact shaped hole and photoelastic resolution). Therefore, the hole diameter was selected to be within the range of 1 to $3-\mathrm{mm}$.

\section{Loading}

An external load was applied to the model by a smooth surface finished disk made of acrylic acid resin (300-mm in diameter and 8- $\mathrm{mm}$ in thickness) 
using the loading system shown in figure 1. Normal and tangential load can be applied by lever arrangements. In most experiments a normal load of 77-kg was applied, taking into account the mechanical strength of contacting materials and the extent of the isochromatic fringe pattern in the model. The Hertzian contact width was found to be approximately 7-mm in these cases. For some experiments, a disk of polycarbonate resin (5-mm in thickness) was used. Except for a slight difference in Hertzian contact width, no difference can be observed in the stress distribution characteristics obtained with the two disks.

Analysis

Prior to each experiment the model was annealed and cured in a temperature-controlled furnace in order to eliminate the residual stresses brought about during the model-making process and by the so-called time-edge effect.

In photoelastic analyses, two kinds of information can usually be obtained: (1) the isochromatics, or loci of points at which the value of maximum principal shear stress is constant, and (2) the isoclinics, or loci of points which exhibit the same inclination angle of the principal stresses. It was difficult, however, to obtain fine and resolvable isoclinics corresponding to the highly ordered isochromatic fringes which can be observed even with a simple polariscopic system and a reasonable model size. Therefore, in most analyses the distribution of maximum shear stress, that is, a half difference in principal stresses, was determined exclusively by paying attention to the isochromatic pattern around the hold. At a free boundary of a peripheral surface of the hole along which no external forces are applied, one of the principal stresses normal to the surface is zero. 
Therefore, the remaining principal stress parallel to the boundary surface can be determined uniquely by the isochromatic fringe order.

Analytical results obtained in such a manner could, therefore, offer information concerning the mechanism of rolling contact fatigue.

I sochromatic photographs were taken in a dark background (i.e., in a circular polarized light polariscope). The nomenclature employed in this study is shown in figure 2 .

\section{RESULTS}

Representative isochromatic patterns beneath the disk are shown in figure 3. These were obtained with a hole and without a hole. The stressraising effect of the hole appears distinctly, since fringes having the number of higher order can be recognized at the area close to the hole edge (fig. 3(b)). The stress concentration around the hole is indicated in figure 4. A circumferential principal stress located at a point on the hole edge can be determined from the number of ordered isochromatic fringes which intersect with the hole edge at the same location (fig. 4(a)). The stress distribution determined by isochromatic fringes around the hole is indicated with a solid line in figure $4(b)$. The dotted line represents the stress distribution estimated from a theoretical analysis by Tamate for the case of a contact between a rigid stamp having a flat surface of finite width and a half-spaced elastic solid (ref. 5 ).

Certainly there are marked differences between the two analyses. Photoelastic fringe patterns do not, however, offer a substantially different pattern between the two, especially around the hole (fig. 5). Therefore, it is reasonable to compare the results directly with each other. Both of the results in figure 4 (b) show a similar pattern in the stress distribution. A large amount of stress concentration is observed at both 
the left and the right side of the hole, the location of which is denoted at the -90 and +90 degree points, respectively, as was defined in figure 2 . The magnitude of the stress located at these regions reaches $1.5 P_{\max }$ as determined by the photoelastic analysis, where $P_{\max }$ means the maximum Hertzian pressure obtained under the condition of no hole. The maximum shear stress $\tau_{\max }$, that is, a half-circumferential stress in this study, reaches $0.75 \mathrm{P}_{\max }$, which exceeds twice the maximum shear stress $0.30 P_{\max }$ found to occur beneath the contact surface having no hole. The stress at the same location obtained from a theoretical estimation is, however, larger. The difference may be caused either by differences in loading conditions or configurations.

A theoretical estimation shows a slight tensile stress appeared near the bottom of the hole, while photoelastic analysis indicates all the stress is compressive around the hole. Even if it is small in magnitude, a tensile stress may act detrimentally in the fracture process of practical components under conditions of Hertzian contact. Additional analyses may be necessary in order to determine the stress distribution in more detail at the area where a tensile stress is predicted to occur. Photoelastic resolution in this study was not satisfactory at the upper and lower areas of the hole. In this paper, analytical conditions were so taken as to cause no tensile stress at the peripheral surface. Since the maximum shear stress has been regarded as a primary stress causing various characteristic phenomena concerning the rolling contact failure, much attention was paid exclusively to the stress distribution at the left and the right side of the hole where a relatively large amount of shear stress concentration occurs.

The analytical results presented herein are represented by the term $\tau_{\max }$ for maximum shear stress as a matter of convenience. In addition, 
attention was paid to the stress distribution at the right half of defects, since defects are hole-shaped and symmetrical.

The stress concentration around the hole obtained by varying the hole diameter are represented in figure 6 . Figure $6(b)$ shows their stress distributions and figure $6(a)$ indicates both variations of the greatest maximum shear stress $\tau_{\max }^{*}$ and its location $\theta^{*}$ on the hole edge with hole diameter. The stress $\tau_{\max }^{\star}$ increases, but its location $\theta^{\star}$ scarcely changes with the magnitude of hole diameter. As expected, $\tau_{\max }^{*}$ finally reaches zero with an extrapolation of the decrease of hole diameter, which is plotted in the figure by a dotted line.

Figure 7 presents the relationship between the stress concentration and the distance of the hole from the contact surface. Stress distributions are indicated in figure $7(b)$ and variations of $\tau_{\max }^{\star}$ and $\theta^{*}$ are plotted against the distance. The stress $\tau_{\max }^{\star}$ decreases uniformly with an increase in the depth of hole and its location $\theta^{*}$ changes slightly within a range of 10 degrees by varying the non-dimensional depth over the range of 0.50 to $1.5 \mathrm{~d} / \mathrm{b}$.

It is well known that tangential traction located at the contact surface has a significant influence on rolling contact fatigue (ref. 6). An example of the effect of tangential load on the stress distribution is shown in figure 8. The radial ordinate is graduated in numbers of fringe order so as to magnify the variation of the effect. The magnitude of maximum shear stress, $\tau_{\max }$, is one-twelfth of the number of the fringe order $N$, that is, $\tau_{\max }=1 / 12 \mathrm{~N}\left(\mathrm{~kg} / \mathrm{mm}^{2}\right)$. Therefore, the effect of tangential load is relatively small, although the coefficient of tangential traction, 0.1 , is larger than that usually predicted in practical rolling contact applica- 
tions. The effect of this load on the stress concentration around a holetype defect is, therefore, concluded to be negligibly small.

Components in rolling contact applications usually experience repetitive loading. Therefore, in order to discuss the mechanisms of rolling contact fatigue, it is necessary to obtain the stress variation over which an element in a component is exposed during the course of rolling contact.

The stress distribution behavior changes with the variation of horizontal distance between the hole and the Hertzian contact area as is illustrated in figure 9. The photograph of figure 9 shows a representative isochromatic pattern obtained under the contact condition in which the Hertzian contact area deviates from the location directly over the hole. Locations where marked stress concentrations are observed shift along the hole edge, depending on the horizontal distance. The magnitude of the largest maximum shear stress decreases and its location deviates from the \pm 90 degree point with increasing distance. The variations on the right half of the hole edge plotted against the distance under several conditions are represented in figure 10. Although it has already been pointed out in the descriptions of the individual effects, hole size, location of the hole from the surface and tangential load do not change dramatically in the characteristics of their behavior by varying the position of Hertzian contact area.

These relationships do not give exact stress amplitudes in certain fixed directions. They are, however, useful for discussing where an incipient micro-crack initiates, because an area which experiences a severe stress concentration repeatedly can be considered as one of principal sources for crack formation during the rolling contact process. 


\section{DISCUSSION}

Recently, a number of reports have indicated that a large number of all failures in rolling contact elements is associated with severe surface defects or stress raisers.

However, Lundberg and Palmgren's type of life prediction formulation has been frequently quoted and applied to practical rolling contact problems. This prediction was developed assuming that most failures start in the subsurface zone of high shear stress below the rolling contact surface. This situation seems to occur since there is ample evidence which indicates that several metallurgical phenomena, deformations or micro-structural alterations, for example, take place in the subsurface high-stress zone (refs. 7 to 9). Furthermore, micro-cracks can be frequently observed propagating near or along this area, the metallurgical character of which is different from the matrix. It is still debated whether or not the deformed area and stress-altered micro-structures are: (1) a primary source for initiation of micro-cracks leading to the final failure, (2) these areas facilitate the propagation of cracks that are initiated elsewhere, or (3) do not take a significant part in the rolling contact failure.

It is well known, however, based on the experimental results, that fatigue life is shortened by pre-existing defects such as nonmetallic inclusions, voids or other metallurgical defects.

In this study, a simple hole-type defect was assumed existing in the matrix and a large amount of stress concentration could be observed in the vicinity of the hole as expected. The stress concentration could be analyzed accurately. The magnitude of the stress concentration was observed to increase with increasing hole diameter. Conversely, the smaller the hole size, the less significant is the influence of the defect. Figure $6(a)$ 
suggests that there is a critical size below which the magnitude of stress concentration is smaller than the ordinary maximum shear stress (0.301 $\mathrm{P}_{\max }$ ) occurring under the condition of Hertzian contact and, therefore, the influence of the defect becomes negligible. When the location of the hole is shifted up close to the surface, the magnitude of the stress concentration increases uniformly and accordingly a more detrimental influence might be produced on the rolling contact failure.

If the hole diameter exceeds the size examined herein, a more intensified stress concentration might be obtained. In such a case, however, the ratio of the hole diameter to the Hertzian contact width departs from a reasonable value encountered in practical problems. Further, the tensile stress is under such circumstances predicted to occur near the upper side of the hole. Therefore, the characteristics of such a problem are substantially different from those of the present study.

The results obtained in this study are similar to the experimental results discussed by Soda for the effect of inclusions existing in materials (ref. 10). These results also indicate that even when the defect is located near the classical nigh-shear stress zone $(0.786 b)$, the stress concentration is not emphasized in the sense that there is an interaction between the stress field due to the defect and the stress field associated with the ordinary Hertzian contact. Therefore, if the defects located near the subsurface nigh-stress zone have a harmful influence on the rolling contact fatigue, this effect is better understood with the mechanism increasing the probability for the occurrence of failure due to the superposition of the defect and conventional high-shear stress zone, and not by emphasizing the stress concentration due to the interaction of these two effects. 
On the other hand, many investigators have reported cracks propagating parallel to the rolling contact surface in both practical applications and bench tests. In the case of a material containing inclusions, incipient micro-cracks have been frequently observed to the right or left side of their peripheral surfaces.

In a more exact discussion of the mechanism of rolling contact fatigue, it is necessary to formulate the fracture criterion applicable to the rolling contact fatigue and to determine all the stress components contributing to the crack formation in the fatigue process.

The results of this study, however, show that even when the Hertzian contact area deviates from the hole, the stress concentration takes place at the restricted area near the left and right side of the hole edge. Since the maximum shear stress, $\tau_{\max }$ decreases with the deviation, the area where possible damage seems to accumulate causing a micro-crack should further contract toward the \pm 90 -degree position. Therefore, the results correspond well with rolling contact fatigue cracks observed in the vicinity of inclusions.

The contours of stress distributions around the hole are very similar morphologically to the so called "butterfly" which can be observed near an inclusion in a bearing material undergoing cyclic stresses. The analyses should be extended to include a discussion of the mechanism of formation of the "butterfly." Since a crack initiated in a material may change the stress distribution, alternate analyses must be conducted to explain crack propagation.

The magnitude of the tangential traction, in this study, is larger than that encountered in practical systems. However, the effect of the tangential traction on the stress concentration is relatively small. This phe- 
nomenon predicts that in the case of incipient microcracks initiating beneath the surface, the tangential traction does not have a significant role. This tendency should be compared with the fact that for the surfaceoriginated mode of rolling contact fatigue there is a marked influence of tangential traction (ref. 6).

\section{CONCLUSIONS}

The characteristics of the stress distribution around a hole-type defect were described under the condition of Hertzian contact with respect to several parameters; that is, loading, hole diameter and the location of the defect (hole). The following conclusions are drawn from the results obtained:

1. A high stress concentration, which has a high stress gradient, exceeding the conventional maximum shear stress, can be observed in the vicinity of the defect (hole). Analytical results indicate a similar tendency to that observed in rolling contact fatigue studies for materials containing inclusions.

2. Taking into account a stress amplitude which is brought about by varying the distance between the position of the defect (hole) and contact area, the greatest deterioration may be concentrated at a restricted area near the left and right hand sides of the peripheral surface of the defect. 3. Tangential traction has only a slight influence on the stress concentration around the defect (hole).

Professor T. Hirata (Tokyo University of Agriculture and Technology) allowed us to use the polariscope. 
REFERENCES

1. Chiu, Y. P. and Liu, J. Y., "An Analytical Study of the Stress Concentration Around a Furrow Shaped Surface Defect in Rolling Contact," ASME Trans., 92, pp 258-263 (1970).

2. Leibensperger, R. L. and Brittain, T. M., "Shear Stresses Below Asperities in Hertzian Contact as Measured by Photoelasticity," ASME Trans., 95, pp 277-286 (1973).

3. Keer, L. M., Bryant, M. D. and Haritos, G. K., "Subsurface Cracking and Delamination," Solid Contact and Lubrication, ed. by H. S. Cheng and L. M. Keer, American Society of Mechanical Engineers, AMD Vol. 39 (1980), pp. 79-95.

4. Hills, D. A. and Ashelby, D. W., "A Fracture Mechanics Approach to Rolling Contact Fatigue," Tribology International, 12, 3, pp 115-119 (1979).

5. Tamate, 0., "On a Contact Problem of an Elastic Half-Plant with a Circular Hole," JSME Trans., 30, 218, pp 1212-1219 (1964).

6. Soda, N. and Yamamoto, T., "Effect of Tangential Traction and Roughness on Crack Initiation/Propagation During Rolling Contact," Presented at the ASLE Annual Meeting, Pittsburgh, PA (May 11-14, 1981).

7. Shima, M., Okada, K., Kimura, Y. and Yamamoto, T., "Measurements of Subsurface Plastic Flow in Rolling Contact," Junkatsu; J. Jpn. Soc. Lubr. Engr.., 25, 12, pp 817-824 (1980).

8. Martin, J.A., Borgese, S. F. and Eberhardt, A. D., "Microstructural Alterations of Rolling - Bearing Steel Undergoing Cyclic Stressing," ASME Trans., 88, pp 555-567 (1966).

9. O'Brien, J. L. and King, A. H., "Electron Microscopy of Stress-Induced Structural Alteration Near Inclusions in Bearing Steels," ASME Trans., 88, pp 568-572 (1966).

10. Soda, N., Bearings, Iwanami Publishing Co., Tokyo, pp. 157-169 (1964). 

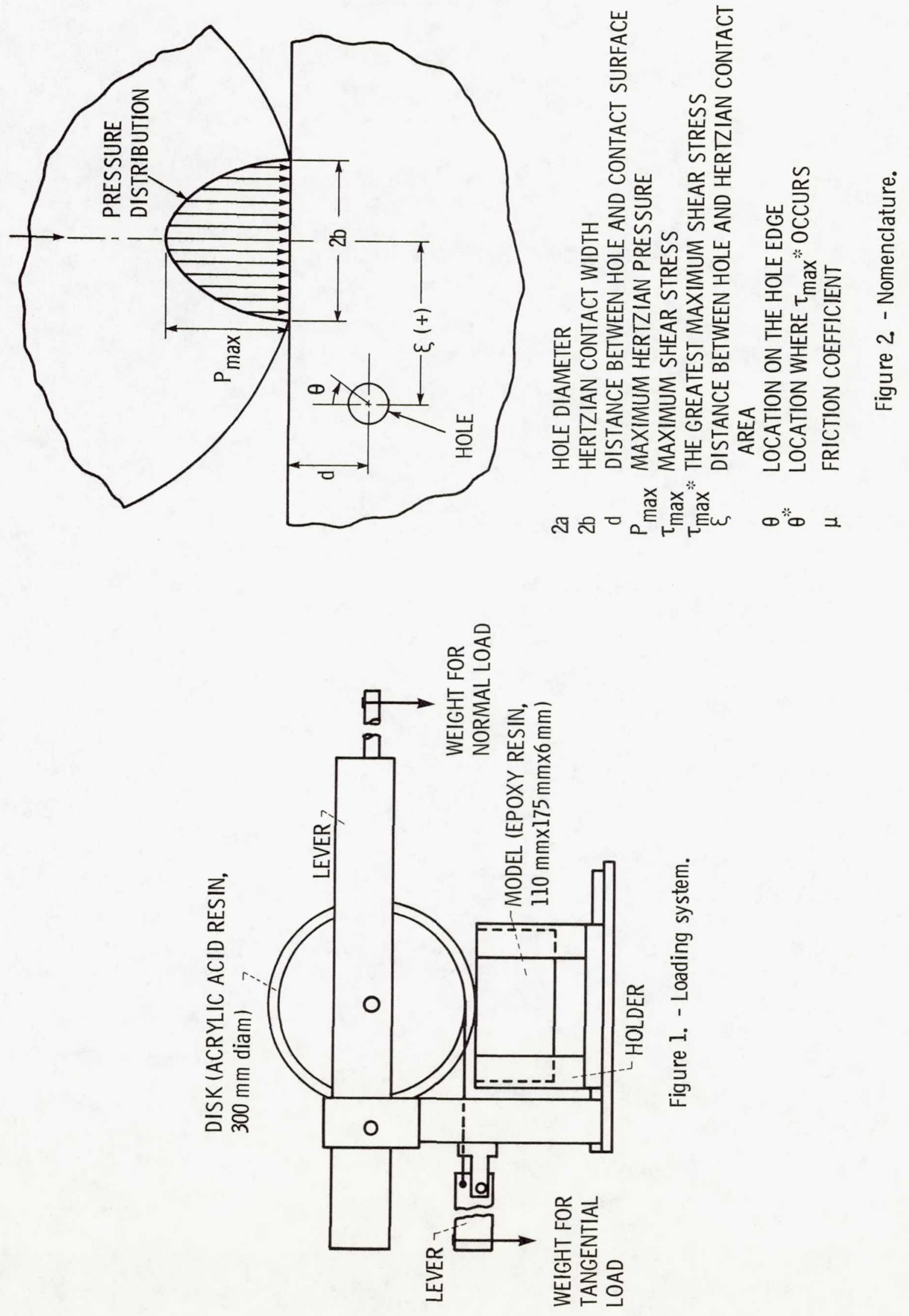


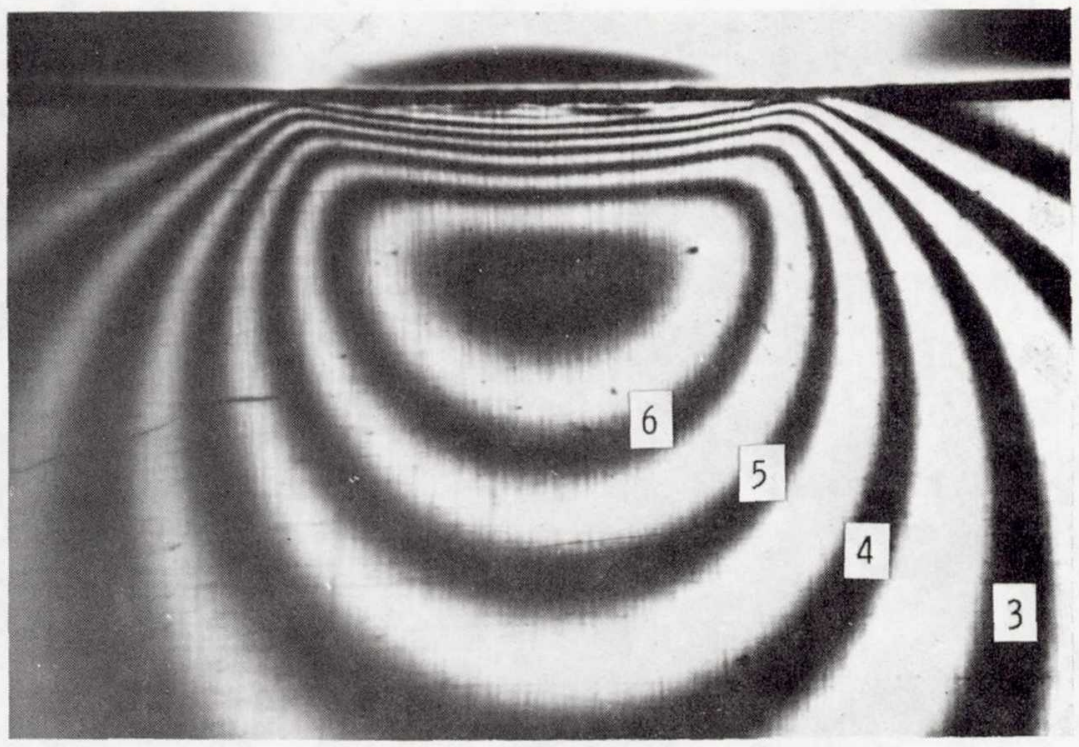

(a) ORDINARY ISOCHROMATIC PATTERN BELOW DISK (NO HOLE).

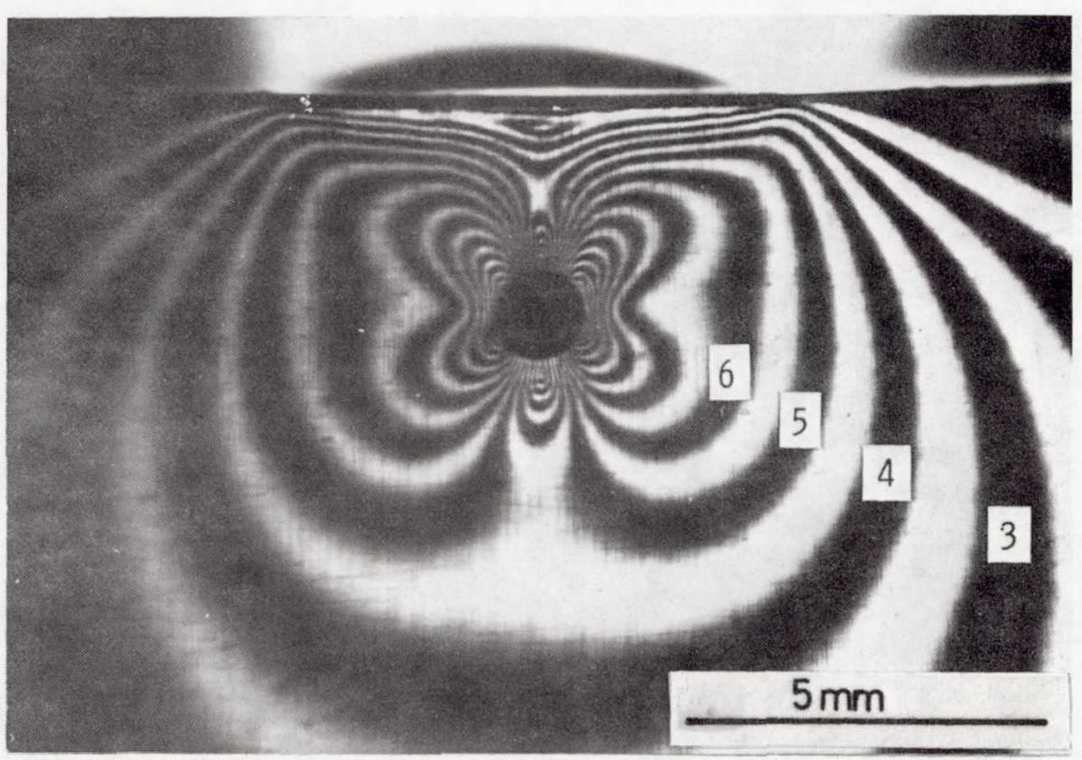

(b) ISOCHROMATIC PATTERN OF THE MODEL CONTAINING A HOLE $2 \mathrm{a}=1.0 \mathrm{~mm}(0.29 \mathrm{~b}), \mathrm{d}=3.0 \mathrm{~mm}(0.88 \mathrm{~b})$.

Figure 3. - Representative isochromatic patterns below disk - nor mal load $=61 \mathrm{~kg}, P_{\text {max }}=1.90 \mathrm{~kg} / \mathrm{mm}^{2}, 2 \mathrm{~b}=6.8 \mathrm{~mm}$. Number in the figure denotes isochromatic fringe order. 


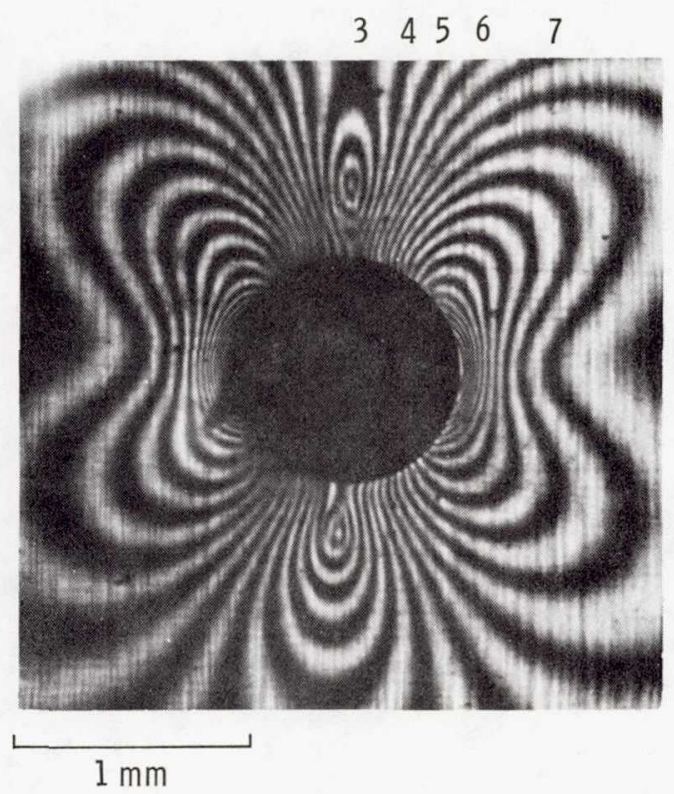

(a)

CIRCUMFERENTIAL STRESS,

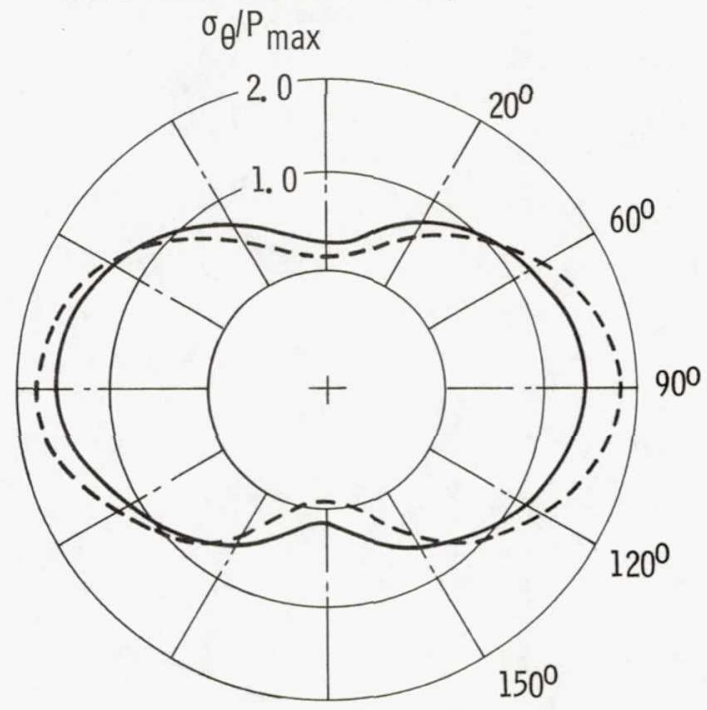

(b)

Figure 4. - Isochromatic pattern and circumferential stress distribution.

(a) Isochromatic fringes around the hole and fringe order; $2 a=1.0 \mathrm{~mm}, d=3.0 \mathrm{~mm}$, normal load $=77 \mathrm{~kg}, P_{\max }=2.33 \mathrm{~kg} / \mathrm{mm}^{2}$.

(b) Circumferential stress distributions around the hole; Solid line: Result by photoelasticity (in the case of contact against disk) $b / d=1.3$, ald $=0.2$.

Dotted line: Estimation by theory (in the case of contact against flat-ended rigid stamp) b/d $=1.0$, $\mathrm{a} / \mathrm{d}=0.2$. 

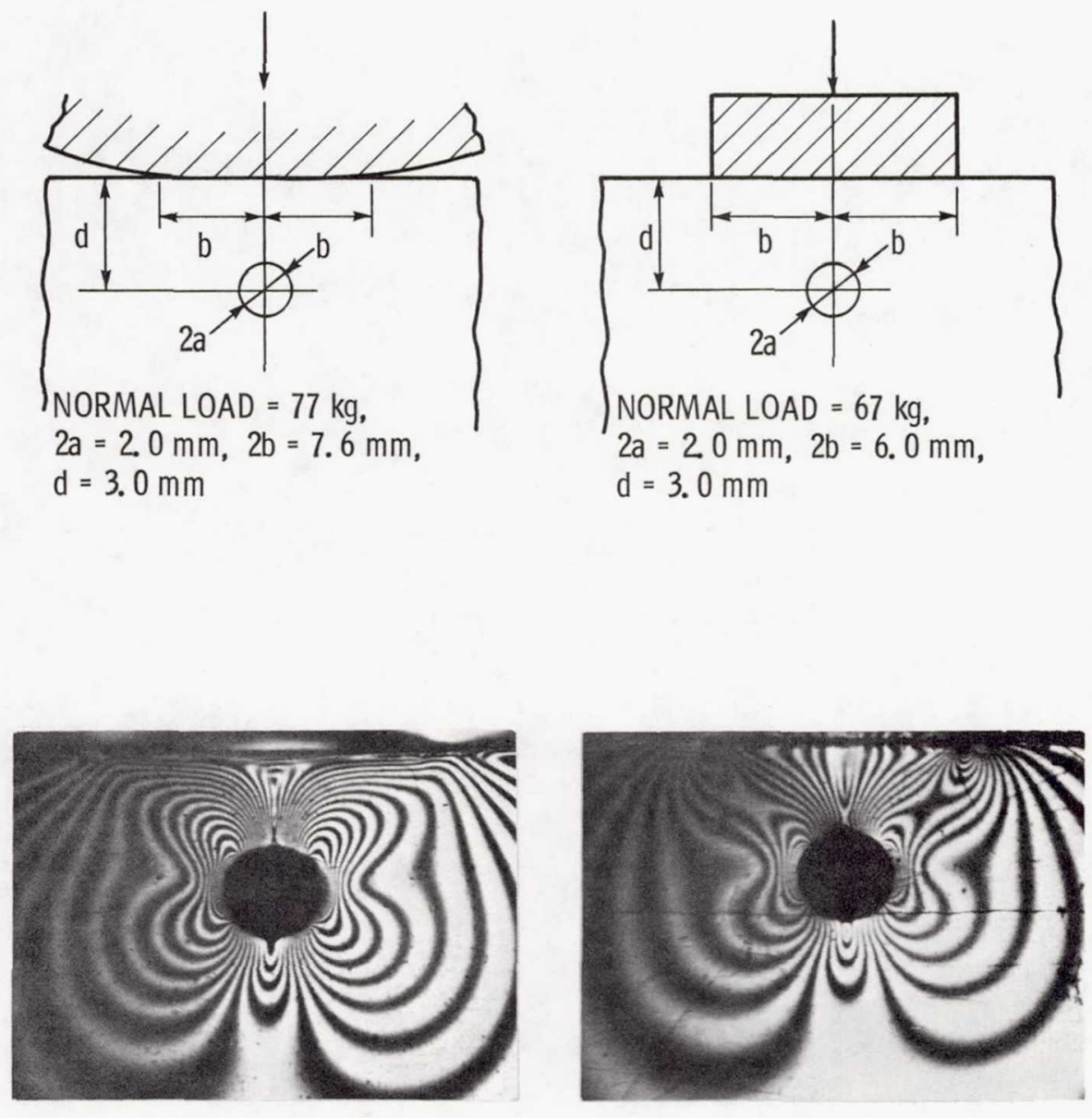

(a)

(b)

Figure 5. - Isochromatic patterns below disk and rectangular stamp.

(a) Isochromatic pattern below disk; $b / d=1.3, a / d=0.3$.

(b) Isochromatic pattern below flat-ended rigid stamp; b/d = 1. 0, a/d = 0. 3 . 

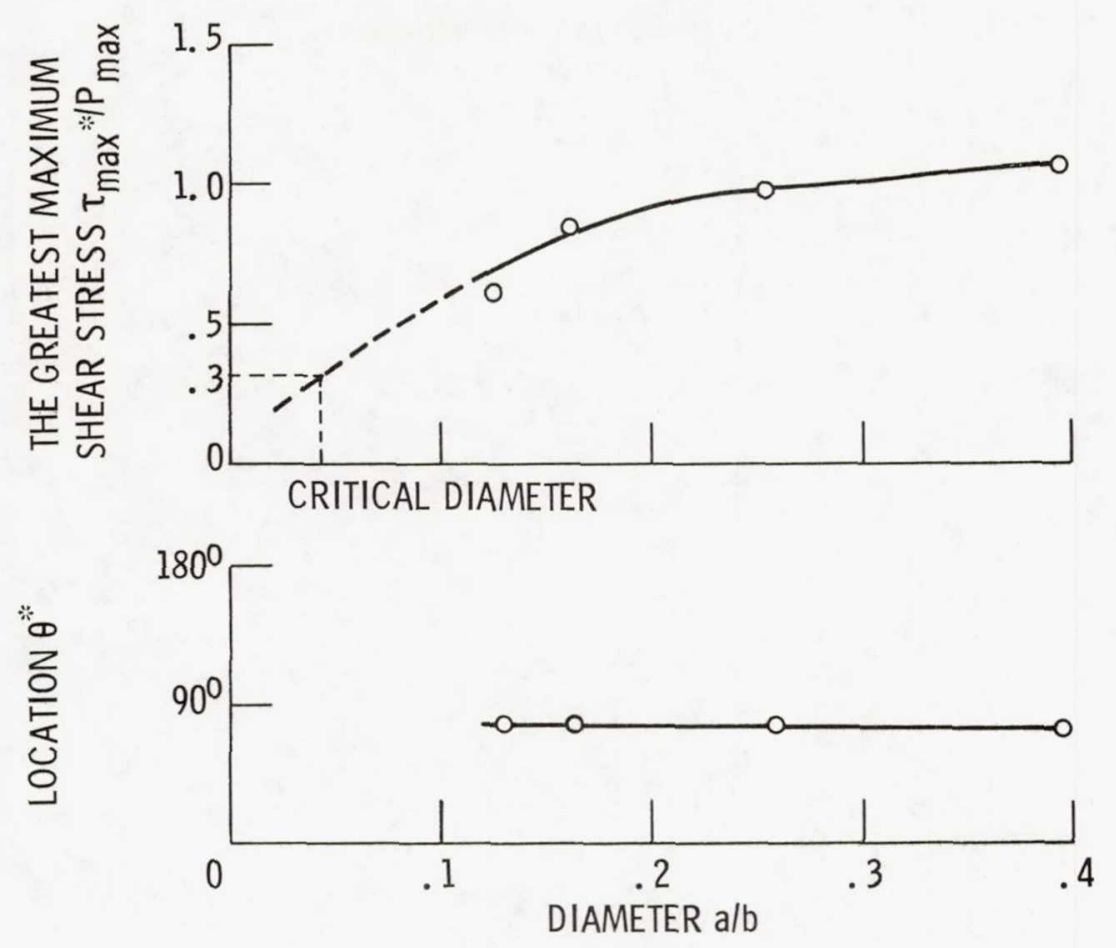

(a)

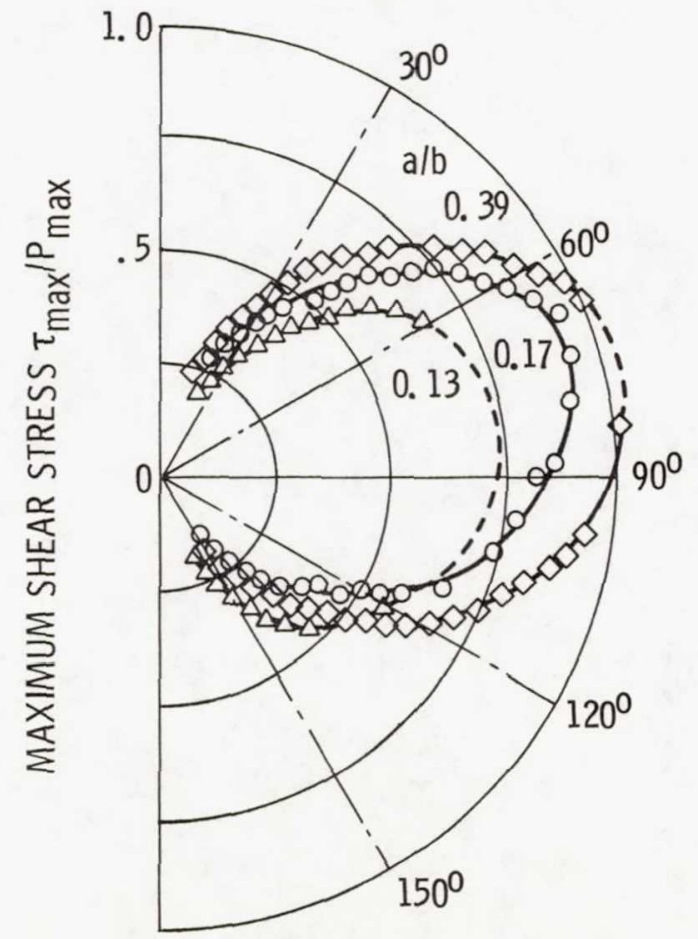

(b)

Figure 6. - Effect of hole diameter on stress concentration; $d=3.0 \mathrm{~mm}(\mathrm{~d} / \mathrm{b}=0.79), \mu=0, \xi=0$.

(a) Variations of the greatest maximum shear stress and its location with hole diameter.

(b) Maximum shear stress distributions around holes. 


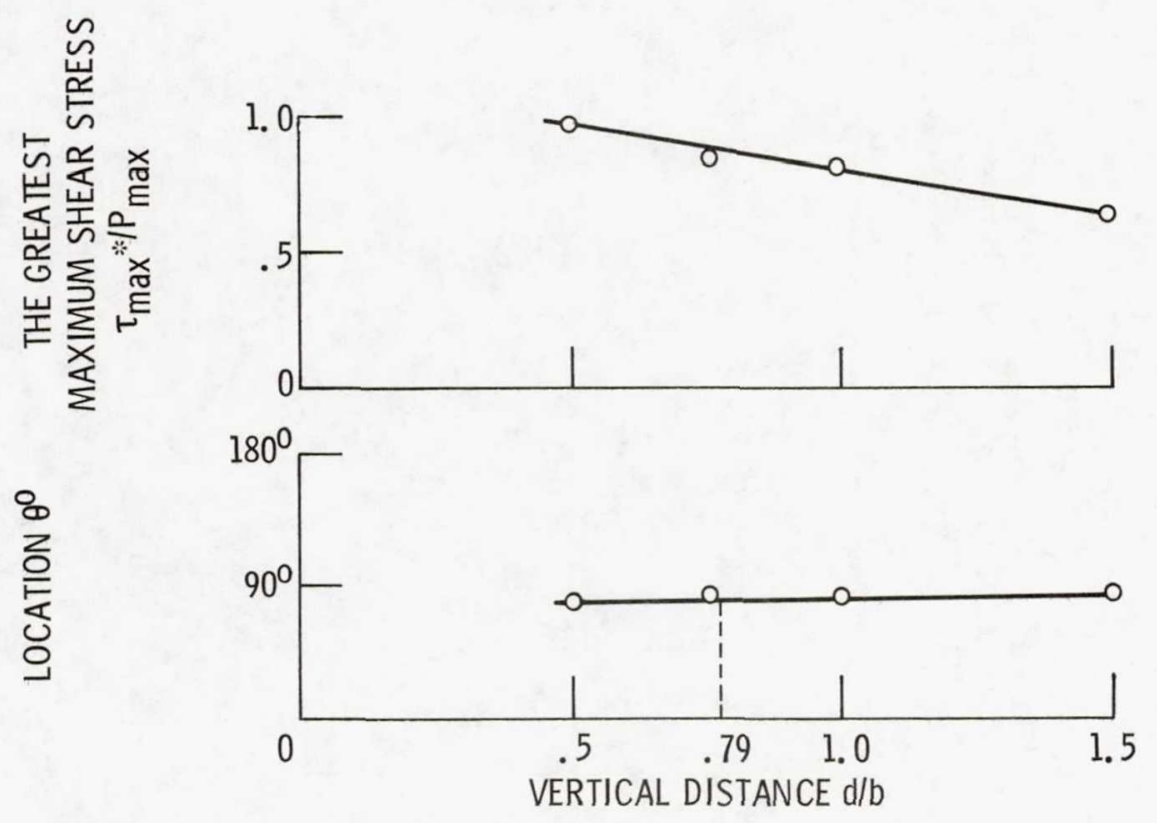

(a)

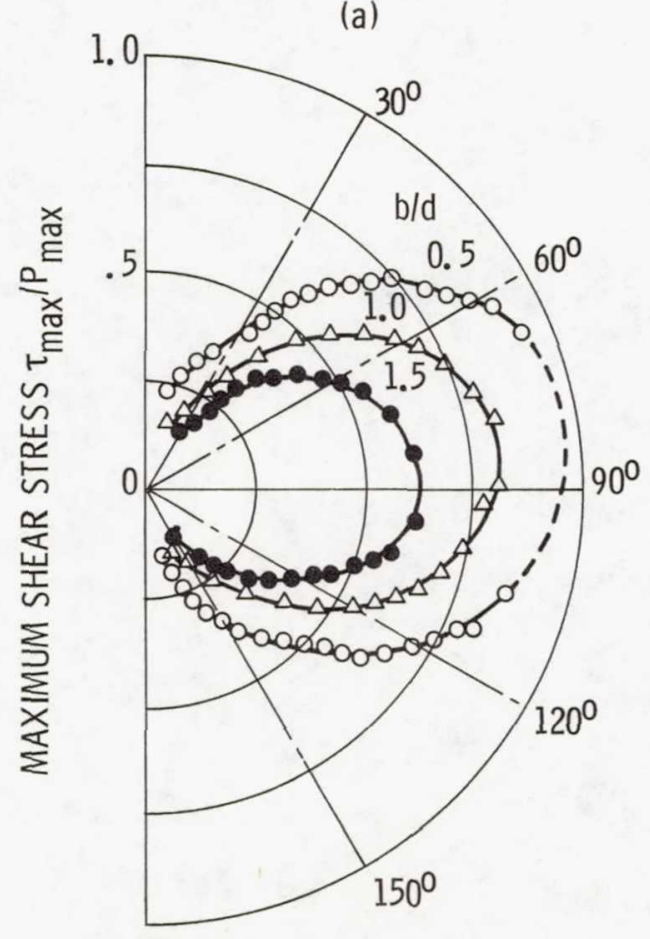

(b)

Figure 7. - Effect of distance between hole and contact surface on stress concentration; $2 \mathrm{a}=1.0 \mathrm{~mm}$ $(a / b=0.13), \mu=0, \xi=0$.

(a) Variations of the greatest maximum shear stress and its location with distance between hole and contact surface.

(b) Maximum shear stress distributions around holes. 


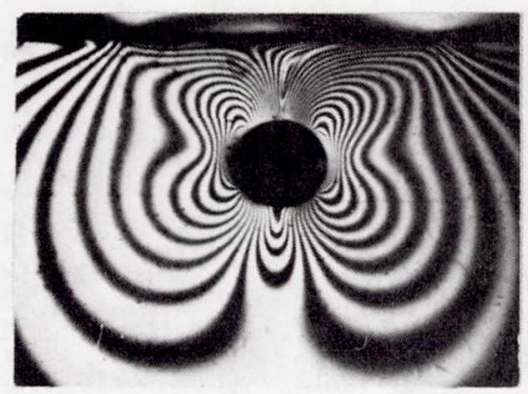

(a)

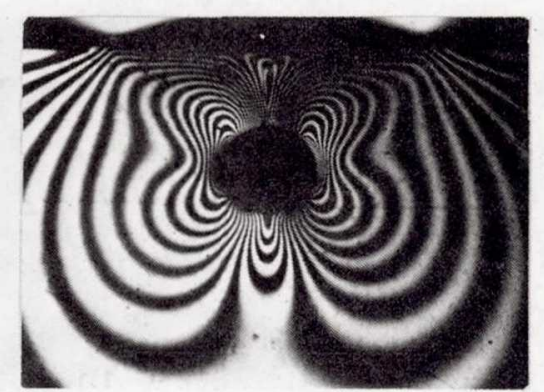

(b)

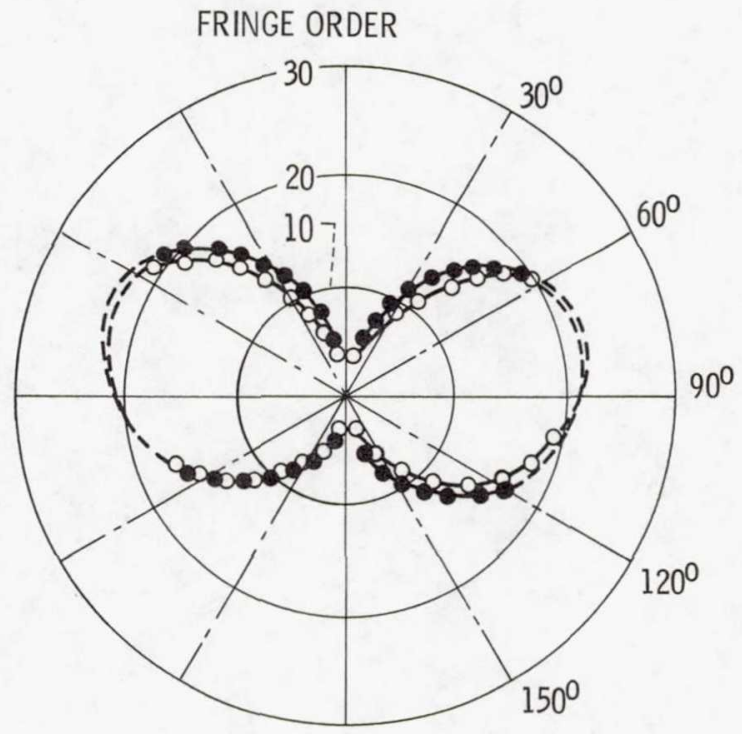

(c)

Figure 8. - Example of effect of tangential force on stress concentration; $2 \mathrm{a}=2 \mathrm{~mm}$ $(a / b=0.26), d=3 \mathrm{~mm}(d / b=0.79)$.

(a) Isochromatic pattern; $\mu=0.1$.

(b) Isochromatic pattern; $\mu=0$.

(c) Stress distributions around the hole.

- In the case of (a)

In the case of (b) 


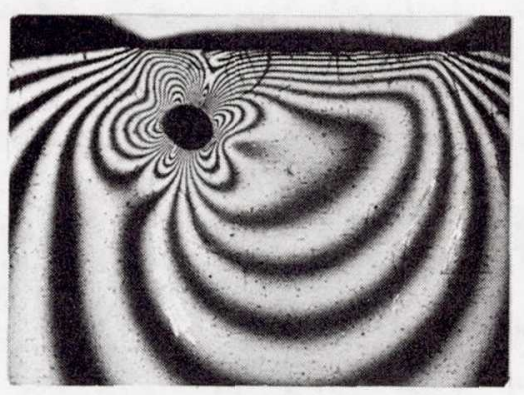

ISOCHROMATIC $(\xi / \mathrm{b}=0.55)$

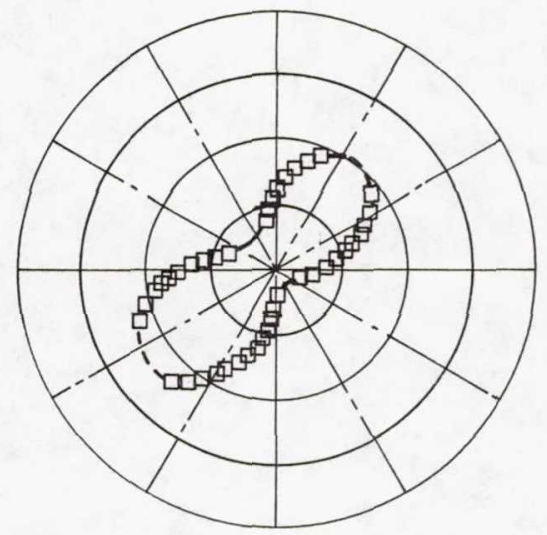

(b)

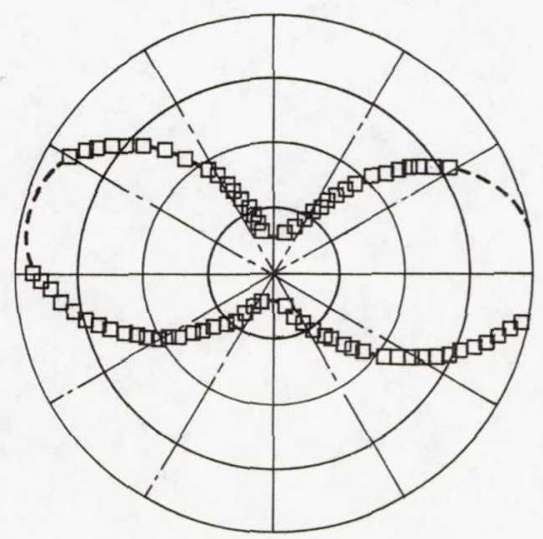

(d)

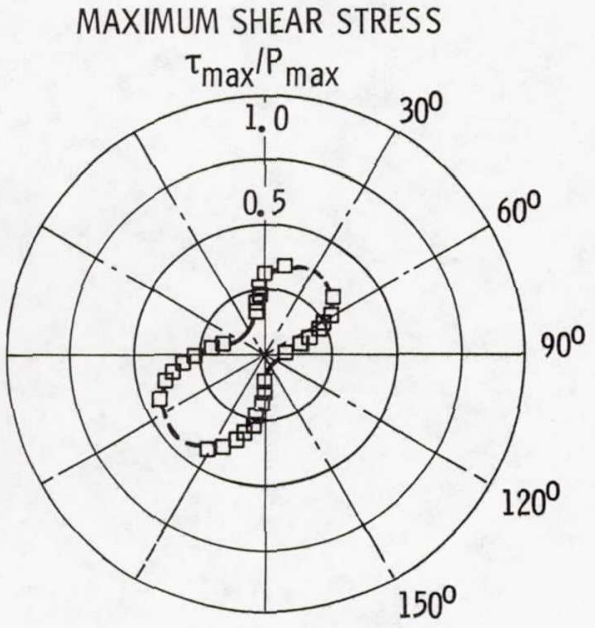

(a)

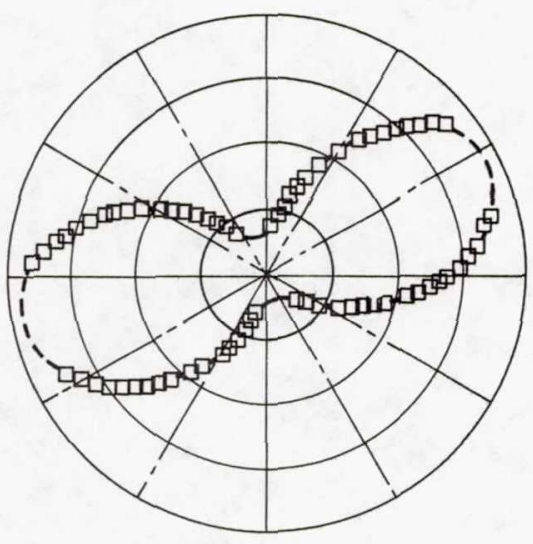

(c)

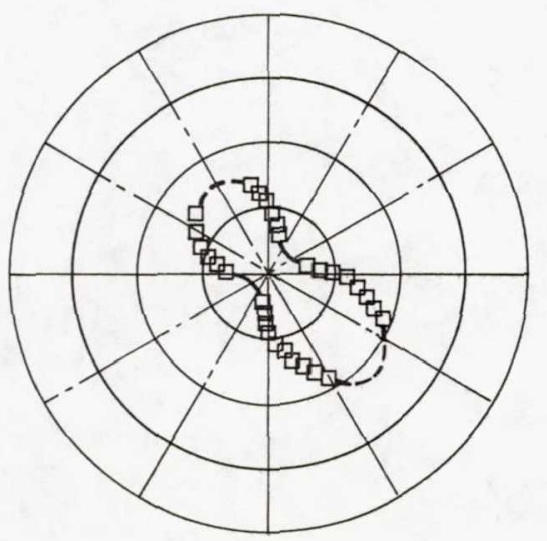

(e)

Figure 9. - Effect of distance between hole and Hertzian contact area on stress concentration; $2 a=2.0 \mathrm{~mm}(a / b=0.26), d=3.0 \mathrm{~mm}(d / b=0.79), \mu=0$.

(a) $\xi / b=-1.5$; (b) $\xi / b=-1.3$; (c) $\xi / b=-0.5 ;$ (d) $\xi / b=0.2$; (e) $\xi / b=1.5$. 


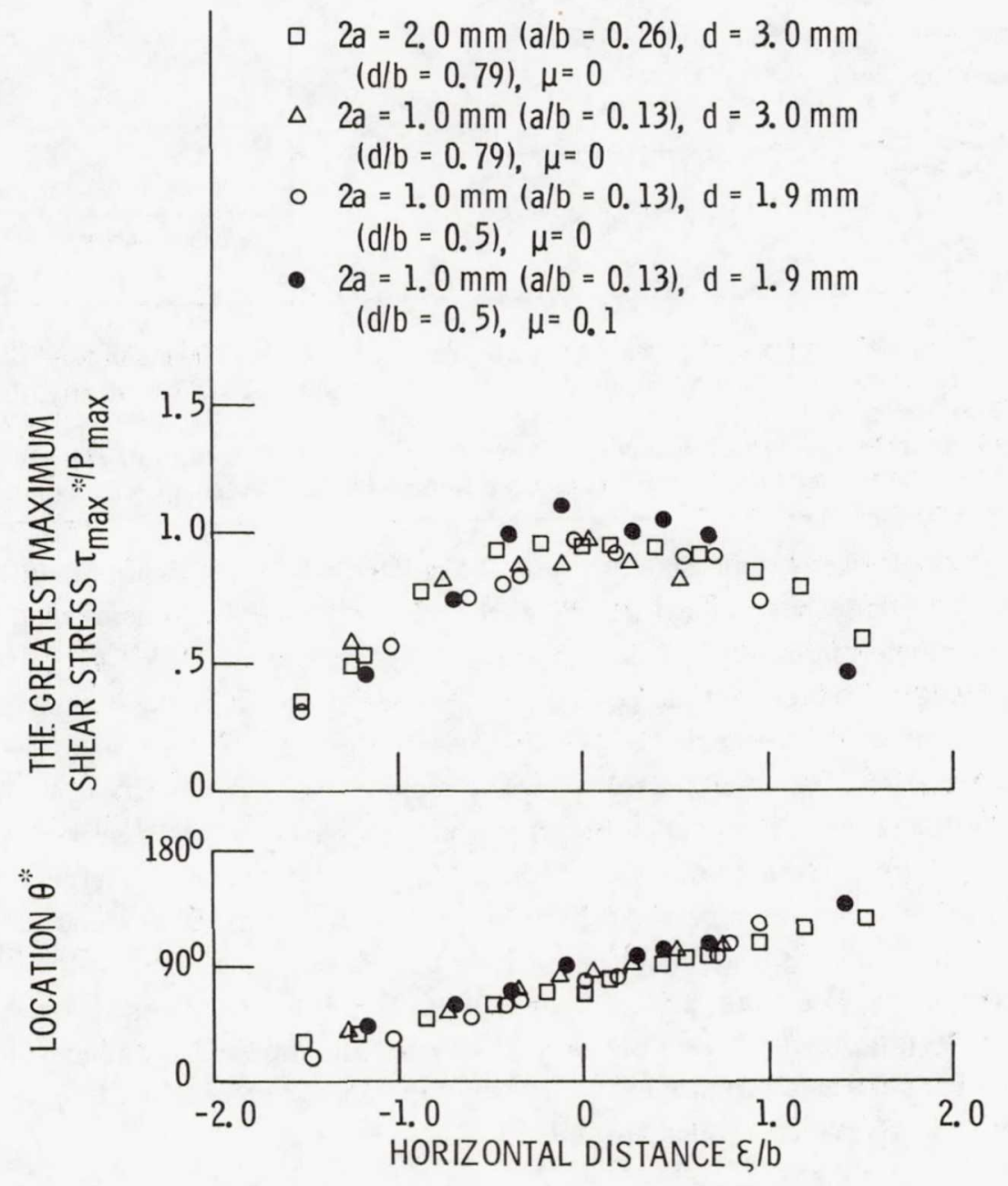

Figure 10. - Variations of the greatest maximum shear stress and its location with distance between hole and Hertzian contact area under various conditions. 


\begin{tabular}{|c|c|c|c|c|}
\hline $\begin{array}{l}\text { 1. Report No. } \\
\text { NASA TM-82649 }\end{array}$ & \multicolumn{2}{|c|}{ 2. Government Accession No. } & \multicolumn{2}{|c|}{ 3. Recipient's Catalog No. } \\
\hline \multirow{2}{*}{\multicolumn{3}{|c|}{$\begin{array}{l}\text { 4. Title and Subtitle } \\
\text { STRESS CONCENTRATION IN THE VICINITY OF A HOLE } \\
\text { DEFECT UNDER CONDITIONS OF HERTZIAN CONTACT }\end{array}$}} & \multicolumn{2}{|l|}{ 5. Report Date } \\
\hline & & & \multicolumn{2}{|c|}{$\begin{array}{l}\text { 6. Performing Organization Code } \\
506-53-12\end{array}$} \\
\hline \multicolumn{3}{|c|}{$\begin{array}{l}\text { 7. Author(s) } \\
\text { Takashi Yamamoto, Masao Eguchi, and Kosho Murayama }\end{array}$} & \multicolumn{2}{|c|}{$\begin{array}{l}\text { 8. Performing Organization Report No. } \\
\text { E-907 }\end{array}$} \\
\hline \multicolumn{3}{|c|}{ 9. Performing Organization Name and Address } & \multicolumn{2}{|l|}{ 10. Work Unit No. } \\
\hline \multicolumn{3}{|c|}{$\begin{array}{l}\text { National Aeronautics and Space Administration } \\
\text { Lewis Research Center }\end{array}$} & \multicolumn{2}{|c|}{ 11. Contract or Grant No. } \\
\hline Cleveland, Ohio 4413 & & & \multirow{2}{*}{\multicolumn{2}{|c|}{$\begin{array}{l}\text { 13. Type of Report and Period Covered } \\
\text { Technical Memorandum }\end{array}$}} \\
\hline \multirow{2}{*}{\multicolumn{3}{|c|}{$\begin{array}{l}\text { 12. Sponsoring Agency Name and Address } \\
\text { National Aeronautics and Space Administration } \\
\text { Washington, D. C. } 20546\end{array}$}} & & \\
\hline & & & \multicolumn{2}{|c|}{ 14. Sponsoring Agency Code } \\
\hline \multicolumn{5}{|c|}{$\begin{array}{l}\text { 15. Supplementary Notes } \\
\text { Takashi Yamamoto, Tokyo University of Agriculture and Technology, Tokyo, Japan and National Research } \\
\text { Council - NASA Research Associate; Masao Eguchi and Kosho Murayama, Tokyo University of Agriculture } \\
\text { and Technology, Tokyo, Japan. } \\
\text { Prepared for the Joint Lubrication Conference cosponsored by the American Society of Mechanical Engi- } \\
\text { neers and the American Society of Lubrication Engineers, New Orleans, Louisiana, October 5-7, 1981. }\end{array}$} \\
\hline \multicolumn{5}{|c|}{$\begin{array}{l}\text { 16. Abstract } \\
\text { Two-dimensional photoelastic stress analyses were conducted for epoxy resin models containing } \\
\text { a hole defect under the conditions of Hertzian contact. Stress concentrations around the defect } \\
\text { were determined as a function of several parameters. These were hole diameter, its vertical } \\
\text { distance from the contact surface and the horizontal distance from the Hertzian contact area. } \\
\text { Also determined was the effect of tangential traction (generated by a friction coefficient of } 0 \text {. 1) } \\
\text { on the stress concentration. Sharp stress concentrations occur in the vicinity of both the left } \\
\text { and the right side of the hole. The stress concentration becomes more distinct the larger the } \\
\text { hole diameter and the smaller the distance between the hole and the contact surface. The stress } \\
\text { concentration is greatest when the disk imposing a normal load is located at the contact surface } \\
\text { directly over the hole. The magnitude and the location of stress concentration varies with the } \\
\text { distance between the Hertzian contact area and the hole. Taking into account the stress ampli- } \\
\text { tude, the area which can be involved in a process of rolling contact fatigue seems to be confined } \\
\text { to a shallow region at both sides of the hole. The effect of tangential traction is comparatively } \\
\text { small on the stress concentration around the hole. }\end{array}$} \\
\hline \multicolumn{2}{|c|}{$\begin{array}{l}\text { 17. Key Words (Suggested by Author(s)) } \\
\text { Rolling contact; Fatigue; Hertzian contact; } \\
\text { Photoelastic analysis; Bearing; Elasticity; } \\
\text { Fracture mechanics }\end{array}$} & \multicolumn{3}{|c|}{$\begin{array}{l}\text { 18. Distribution Statement } \\
\text { Unclassified - unlimited } \\
\text { STAR Category } 37\end{array}$} \\
\hline $\begin{array}{l}\text { 19. Security Classif. (of this report) } \\
\text { Unclassified }\end{array}$ & $\begin{array}{l}\text { 20. Security Classi } \\
\text { Un }\end{array}$ & $\begin{array}{l}\text { this page) } \\
\text { ssified }\end{array}$ & 21. No. of Pages & 22. Price \\
\hline
\end{tabular}

* For sale by the National Technical Information Service, Springfield, Virginia 22161 
National Aeronautics and Space Administration

SPECIAL FOURTH CLASS MAIL BOOK
Postage and Fees Paid National Aeronautics and Space Administration

NASA -451

Washington, D.C.

20546

Official Business

Penalty for Private Use, $\$ 300$ 